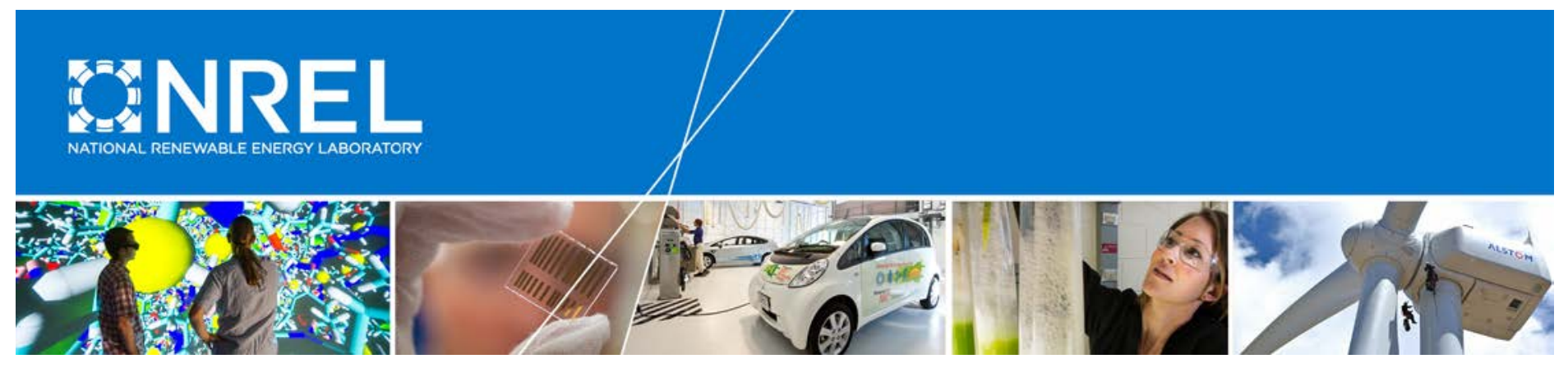

\title{
Software Comparison for Renewable Energy Deployment in a Distribution Network
}

David Wenzhong Gao Alternative Power Innovations, LLC

Eduard Muljadi, Tian Tian, and Mackay Miller National Renewable Energy Laboratory

NREL is a national laboratory of the U.S. Department of Energy Office of Energy Efficiency \& Renewable Energy Operated by the Alliance for Sustainable Energy, LLC

This report is available at no cost from the National Renewable Energy Laboratory (NREL) at www.nrel.gov/publications.

Technical Report

NREL/TP-5D00-64228

February 2017

Contract No. DE-AC36-08GO28308 


\section{Software Comparison for Renewable Energy Deployment in a Distribution Network}

David Wenzhong Gao

Alternative Power Innovations, LLC

Eduard Muljadi, Tian Tian, and Mackay Miller National Renewable Energy Laboratory

Prepared under Task Nos. IGIN.1840, IGIN.1850
NREL is a national laboratory of the U.S. Department of Energy Office of Energy Efficiency \& Renewable Energy Operated by the Alliance for Sustainable Energy, LLC

This report is available at no cost from the National Renewable Energy Laboratory (NREL) at www.nrel.gov/publications.

\section{Technical Report}

NREL/TP-5D00-64228

February 2017

Contract No. DE-AC36-08G028308
National Renewable Energy Laboratory 15013 Denver West Parkway

Golden, CO 80401

303-275-3000 • www.nrel.gov 


\section{NOTICE}

This report was prepared as an account of work sponsored by an agency of the United States government. Neither the United States government nor any agency thereof, nor any of their employees, makes any warranty, express or implied, or assumes any legal liability or responsibility for the accuracy, completeness, or usefulness of any information, apparatus, product, or process disclosed, or represents that its use would not infringe privately owned rights. Reference herein to any specific commercial product, process, or service by trade name, trademark, manufacturer, or otherwise does not necessarily constitute or imply its endorsement, recommendation, or favoring by the United States government or any agency thereof. The views and opinions of authors expressed herein do not necessarily state or reflect those of the United States government or any agency thereof.

This report is available at no cost from the National Renewable Energy Laboratory (NREL) at www.nrel.gov/publications.

Available electronically at SciTech Connect http:/www.osti.gov/scitech

Available for a processing fee to U.S. Department of Energy and its contractors, in paper, from:

U.S. Department of Energy

Office of Scientific and Technical Information

P.O. Box 62

Oak Ridge, TN 37831-0062

OSTI http://www.osti.gov

Phone: 865.576.8401

Fax: 865.576.5728

Email: reports@osti.gov

Available for sale to the public, in paper, from:

U.S. Department of Commerce

National Technical Information Service

5301 Shawnee Road

Alexandra, VA 22312

NTIS http://www.ntis.gov

Phone: 800.553 .6847 or 703.605 .6000

Fax: 703.605.6900

Email: orders@ntis.gov 


\section{Acknowledgments}

This report was funded under the U.S.-China Renewable Energy Partnership through the U.S. Department of Energy's Office of Energy Efficiency and Renewable Energy's International Team. The authors would like to thank the U.S.-China Renewable Energy Partnership for the opportunity to collaborate on the scoping and development of this study.

For their extensive review and comments, the authors would like to thank Mark Laufenberg from PowerWorld Corporation, Roger Dugan from the Electric Power Research Institute, Jason Fuller from the Pacific Northwest National Laboratory, Ping Hsu from San Jose State University, Riming Shao from University of New Brunswick, Mohammad A.S. Masoum from Curtin University, Syed Islam from Curtin University, Arlene Fetizanan from the U.S. Department of Energy, as well as Barry Mather and Fei Ding from the National Renewable Energy Laboratory. The authors also thank Katie Wensuc of the National Renewable Energy Laboratory for editorial review and support. Any errors or omissions are solely the responsibility of the authors. 


\section{List of Acronyms}

COM

CSV

DER

DG

DLL

DSS

EPRI

GUI

$\mathrm{km}$

kVAR

$\mathrm{kW}$

MinGW

MVA

PNNL

PV

VAR component object model

comma separated values

distributed energy resources

distributed generation

dynamic-link library

Distributed System Simulator

Electric Power Research Institute

graphical user interface

kilometer

kilovolt ampere reactive

kilowatt

Minimalist GNU for Windows

megavolt ampere

Pacific Northwest National Laboratory

photovoltaic

volt ampere reactive 


\section{Executive Summary}

The main objective of this report is to evaluate different software options for performing robust distributed generation (DG) power system modeling. The features and capabilities of four widely used simulation tools, OpenDSS, GridLAB-D, CYMDIST, and PowerWorld Simulator, are compared to analyze their effectiveness in analyzing distribution networks with DG.

OpenDSS and GridLAB-D, two open-source software, have the capability to simulate networks with fluctuating data values. These packages allow the running of a simulation each time instant by iterating only the main script file. CYMDIST, a commercial software, allows for time-series simulation to study variations on network controls. PowerWorld Simulator, another commercial tool, has a batch mode simulation function through the "Time Step Simulation" tool, which obtains solutions for a list of specified time points.

PowerWorld Simulator is intended for analysis of transmission-level systems, while the other three are designed for distribution systems. CYMDIST and PowerWorld Simulator feature easyto-use graphical user interfaces (GUIs). OpenDSS and GridLAB-D, on the other hand, are based on command-line programs, which increase the time necessary to become familiar with the software packages. 


\section{Table of Contents}

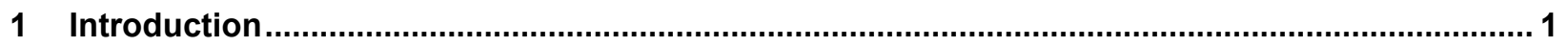

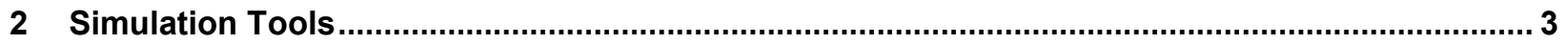

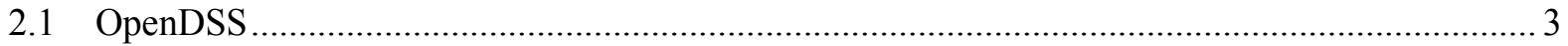

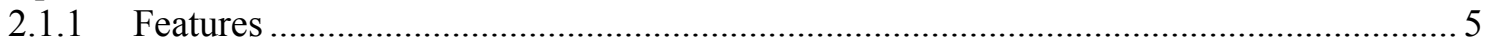

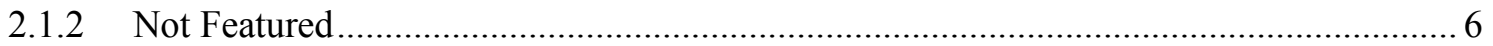

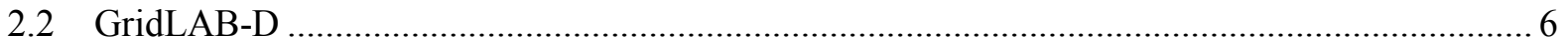

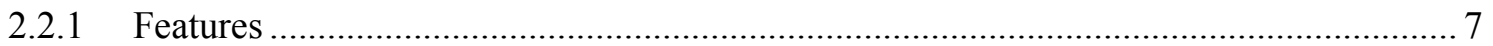

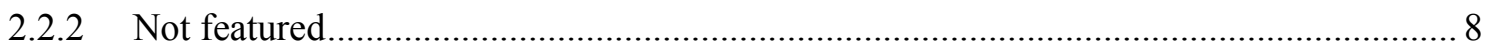

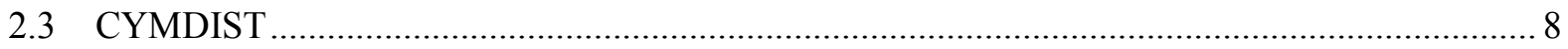

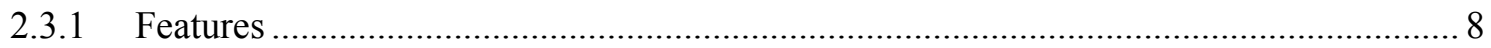

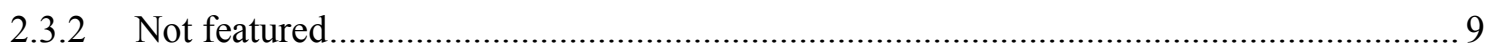

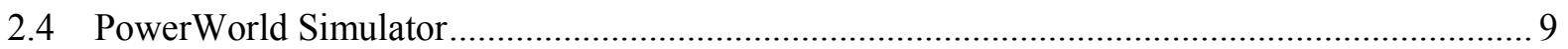

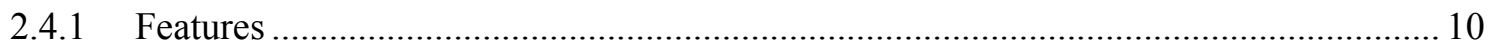

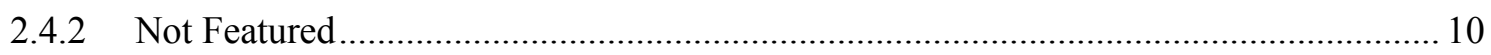

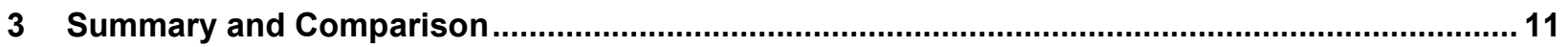

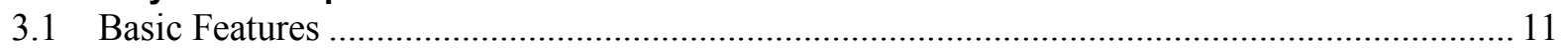

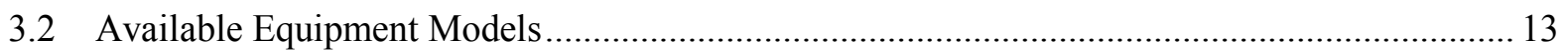

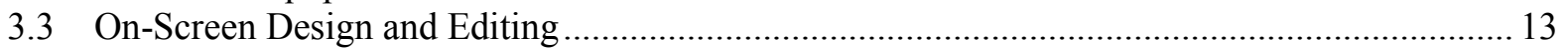

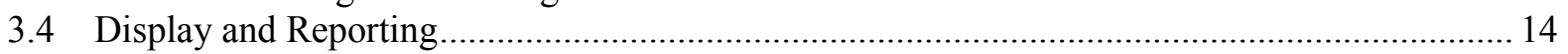

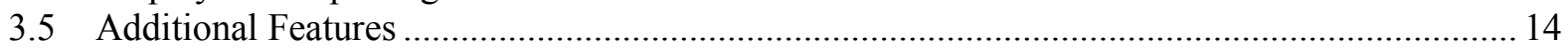

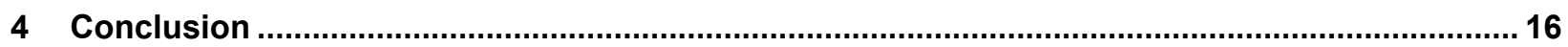

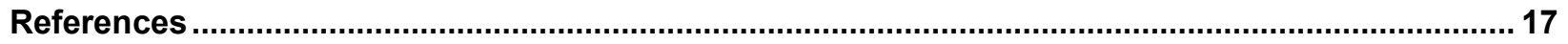




\section{List of Figures}

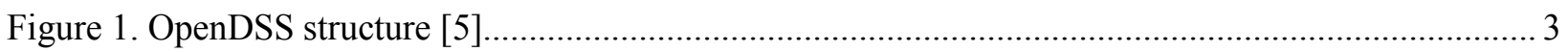

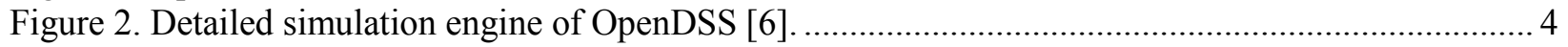

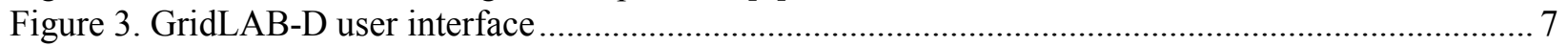

\section{List of Tables}

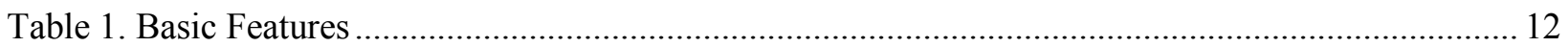

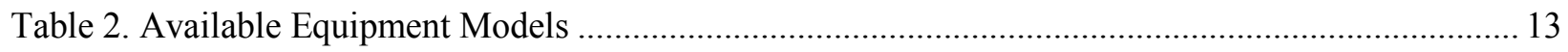

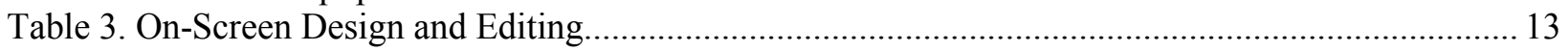

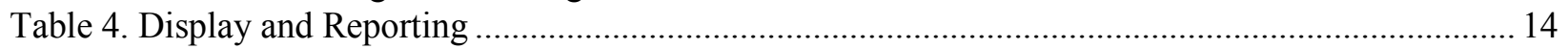

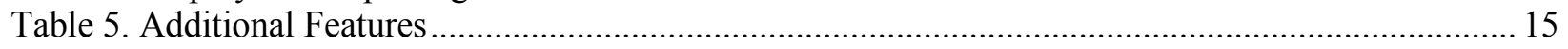




\section{Introduction}

The growing prominence of distributed generation (DG) in various markets, including in the United States and China, brings a new set of complexities and operational challenges to distribution networks and resource planning. Increasing numbers of energy consumers have become net energy producers with the rapid deployment of distributed energy resources (DER), such as rooftop photovoltaic (PV) systems, small wind energy generation systems, and energy storage. Grid operators have taken measures to ensure the reliability and safety of the power grid due to the power fed back into the system. Some specific impacts of DG on the system include:

- Integration of decentralized renewable energy generation resulting in reversal of power flow direction from the load bus or feeder to the transmission network, which may lead to voltage disturbance [1]

- Unbalanced and multiphase distribution power flow

- Overload of upstream grid components from charging electric vehicles

- Risks associated with distributed generators (without anti-islanding protection) failing to disconnect from the grid in case of a fault event.

- Integration of new technologies, such as smart grids, to manage peak demand through load profiling.

Systems that have large quantities of distributed energy resources require advanced modeling and simulation tools ("software package" or "package") to analyze the demanding level of DG input and output data. To help grid planners, regulators, operators, and relevant research institutions understand such tools and determine their suitability for local grids, this report reviews a variety of publically and commercially available packages to determine their suitability and applicability in performing the required analysis for distribution networks that have large penetrations of renewable distributed energy resources. This paper does not offer endorsement of specific tools, but it helps distinguish the characteristics of each.

A number of simulation tools are available to analyze distribution networks. The capabilities of these select packages, mostly intended to compute quasi-steady-state solutions, are reviewed in this report:

- OpenDSS by the Electric Power Research Institute (EPRI) ${ }^{1}$

- GridLAB-D by Pacific Northwest National Laboratory ${ }^{2}$

- CYMDIST by CYME International ${ }^{3}$

- PowerWorld Simulator by PowerWorld Corporation. ${ }^{4}$

\footnotetext{
${ }^{1}$ OpenDSS can be downloaded from https://sourceforge.net/projects/electricdss/.

${ }^{2}$ GridLAB-D can be downloaded from https://sourceforge.net/projects/gridlab-d/?source=directory.

${ }^{3}$ CYMDIST can be downloaded from http://www.cyme.com/software/cymdist/.

${ }^{4}$ PowerWorld Simulator can be downloaded from http://www.powerworld.com/.
} 
Each software package has been developed with different levels of resources and objectives. For example, PowerWorld Simulator is designed to perform simulation on high voltage systems and is mostly used for transmission planning, large-scale renewable energy generators, and management of power markets. ${ }^{5}$ The other three packages are designed for distribution system analysis. While CYMDIST is a commercially available product, OpenDSS and GridLAB-D are open source and free to the public. Therefore, it is important to review each package's performance and functionality based on the context of its development and intention. In addition to providing background information for each package, the review identifies the advantages and disadvantages of each simulation tool based on their capability to accommodating the following:

- Voltage regulation

- Line-loss calculation

- Generation variability

- Load variability

- Short-circuit calculations

- Single-phase or three-phase systems

- Balanced or unbalanced operation.

As each tool continues to evolve with each version, it is advised that potential users of these software packages check the availability of specific features based on the version being considered.

\footnotetext{
${ }^{5}$ PowerWorld Simulator is analyzed here to illustrate the distinctions in functionality and features between transmission level and distribution level simulators.
} 


\section{Simulation Tools}

\subsection{OpenDSS}

The Distribution System Simulator (DSS) is a frequency-domain electrical circuit simulation tool developed by Electrotek Concepts in 1997 for the distribution grid. In 2004, EPRI acquired the package and made it an open-source code program in 2008 known as OpenDSS ${ }^{6}$ [2-4]. It was designed to support analysis of distributed generation interconnected to utility distribution systems and continues to serve as an important analytical tool for distribution utilities.

Programmed in Delphi, OpenDSS can be executed as a stand-alone program. It can also be integrated into other software platforms (e.g., MATLAB, Excel, and PYTHON) by using the MS Windows component object model (COM) interface, which allows interaction among different objects without dictating the methods of implementation. The software is windows based and is not compatible with other operating systems.

Figure 1 illustrates the structure of OpenDSS. The user can interact with the simulation engine by using text scripts, COM interface calls, and user-written dynamic-link libraries. Output scripts can be saved and used by other software programs that can import common CSV formats. MATLAB and Excel are commonly used with OpenDSS to preprocess and post process data.

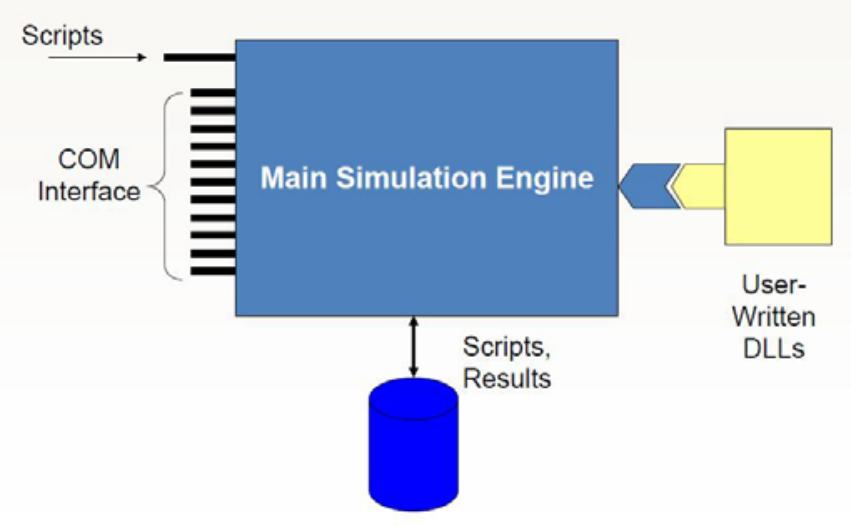

Figure 1. OpenDSS structure [5]

The initial goal of developing this software was to analyze unbalanced, $n$-phase power utility distribution systems in North America. However, OpenDSS can also model European-style distribution systems, which have comparatively simple primary (medium-voltage) system structures but extensive secondary (low-voltage) systems [4].

Many of the software's features are designed to support the analysis of DG interconnections to the distribution system. Combined with transmission system studies, these analyses can provide a holistic assessment of power system response.

\footnotetext{
${ }^{6}$ OpenDSS (64-bit and 32-bit versions) can be downloaded free of charge from www.sourceforge.net.
} 
OpenDSS is capable of capturing both location-specific and time-specific benefits of DG. Sequential-time simulations are essential for modeling variable DG elements, such as renewable generators, electric vehicles, and storage, which do not follow typical load shapes [4].

OpenDSS has several built-in solution modes, including snapshot power flow, daily mode (24 hours, 1 -hour increments), yearly mode (8,760 hours, 1 -hour increments), and duty cycle (time steps ranging from 1 seconds to 5 seconds), to facilitate distribution planning studies and interconnection studies with high penetrations of variable generation.

However, the package also provides flexibility for users to customize solutions. The separate models for controllers (e.g., relays and fuses) and controlled devices (e.g., capacitors and tap changers) enable simulated objects to replicate their physical counterparts in small time increments and allow users to customize controller models. Figure 2 illustrates the detailed components of the main simulation engine of OpenDSS.

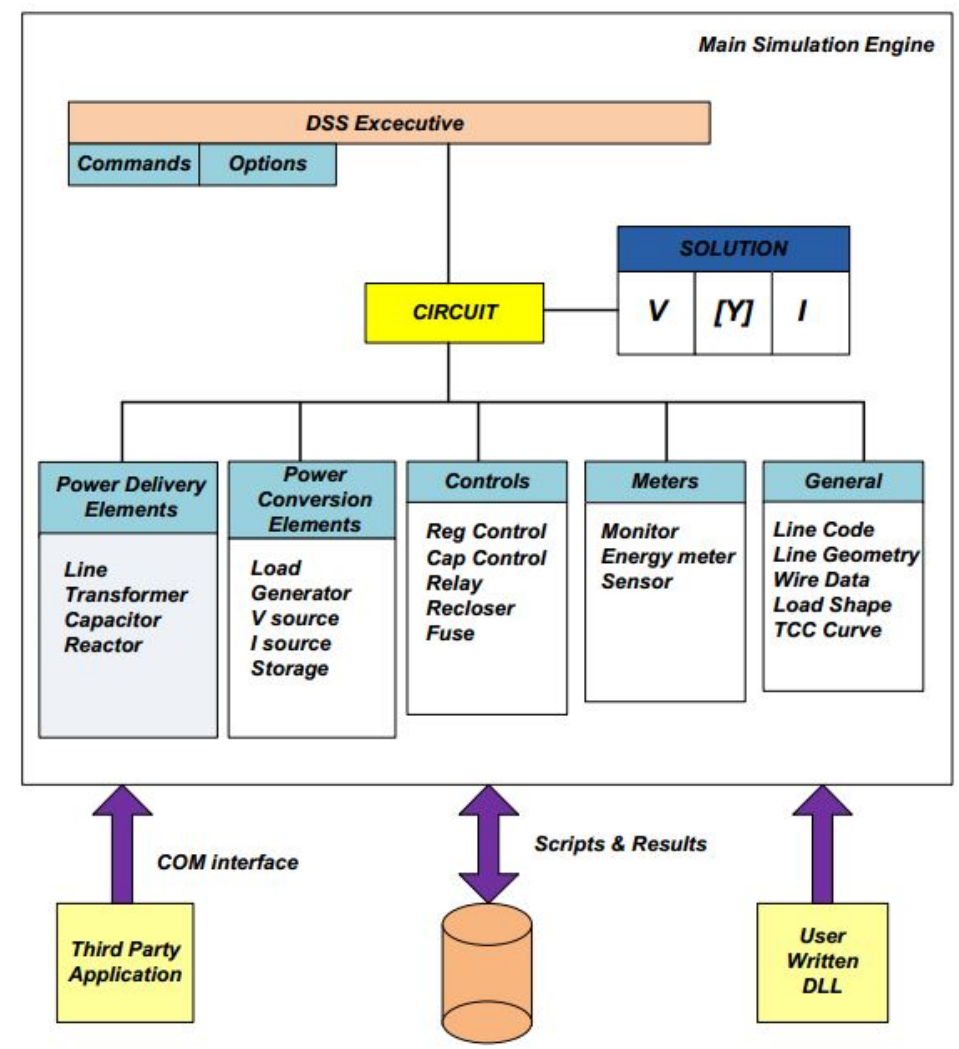

Figure 2. Detailed simulation engine of OpenDSS [6].

Sequential-time simulations, built-in solution modes, and separate models for controllers and circuit elements allow OpenDSS to investigate the fluctuation of renewable resources and assess the impact of interconnecting high penetrations of variable generation. 
While the text-based, multi-window user interface seemingly renders it difficult to build large circuit models, users with expertise in good text editors and scripting language should experience little difficulty. Open-DSS allows users to combine data from different sources for large-scale modeling. The text-based interface enables data conversion and combination of data from difference sources to build a model, including large circuit models.

The software package cannot perform communication simulation functions in smart grids because smart grid communication models are not included in the base program. However, the COM interface allows external communication simulation programs (e.g., ns2 and OpNet) to be incorporated.

The current version of Open-DSS (version 7.6.4) provides seven different generator models along with PVSystem and Storage models. Inverters are included within the PVSystem and generator models. PVSystem objects can be controlled by advanced inverter controls (i.e., the InvControl object) to achieve volt-VAR, volt-watt and other advanced inverter control characteristics. OpenDSS also provides models for fuses, reclosers, and relays whose parameters and technical specifications can be changed by the user. The Relay model has been used in DG interconnection evaluations requiring reverse power and negative-sequence relaying functions.

\subsubsection{Features}

- Grid elements. OpenDSS contains models of different elements in the distribution network related to delivery (e.g., capacitor, line, reactor, and transformer), conversion (e.g., generator, PV system, storage, and load), and control (e.g., capacitor bank control, storage controller, and DG dispatch controller) [4]. Implementing these models enables the package to support elements of the analysis of the distribution power grid with variable generation, such as power loss calculation, short-circuit currents, unbalanced loads, and storage management.

- Preprocessing and post processing. OpenDSS supports csv files, MATLAB, and Excel to preprocess or post process data.

- Compatibility with other applications. OpenDSS can be easily integrated with other software platforms through its COM interface, which allows users to control the simulation from their own software.

- Power flow analysis. Multi-phase models allow OpenDSS to run power flow analysis for radial networks and meshed systems. The software can also perform power flow for unbalanced loads.

- Harmonic analysis. OpenDSS has the unique capability using a harmonics solution mode to perform simulations of harmonic current and voltage distortion in networks.

- Capacitor bank control. OpenDSS can model standard utility capacitor bank control modes, such as voltage, current, kVAR, and time. Voltage override can be applied to any mode; capacitors can be controlled remotely and by dynamic-linked libraries written by the user.

- Short-circuit analysis. OpenDSS has an existing command that can perform short-circuit analysis. It is able to solve for a short circuit while executing a power flow study, as well as solve for transmission overbuild falling on the distribution feeder. 
- Transient stability solution. OpenDSS can perform transient stability analysis, allowing for islanding studies related to distributed generation and microgrids.

- Voltage regulator models. OpenDSS has a realistic regulator model with several options, such as regulator controls (with consideration for line drop compensation), remote bus regulation, and automatic reversing.

\subsubsection{Not Featured}

- On-screen design and editing. OpenDSS is a scriptable distribution system simulation tool. It may be scripted via text commands, text files, or through calls to functions in the COM interface from user-written programs. Thus, every single element is required to be connected to the model through the command line. OpenDDS does not support online editing, zooming, or dragging and dropping shapes. However, a separate, stand-alone output post-processing program can produce circuit plots of a model.

\subsection{GridLAB-D}

The Pacific Northwest National Laboratory (PNNL), under the U.S. Department of Energy, first introduced GridLAB-D in 2008 as an open-source simulator to model power flow, residential load modeling, and retail markets. The current version of GridLAB-D (V3.2) ${ }^{7}$ has functions capable of facilitating energy-efficiency impact analysis and renewable energy integration. It has a residential model, consisting of a series of residences and appliances, which integrates with the distribution system. The market module combines market (i.e., auction) simulation and appliance controllers that are responsive to market price, making it suitable for demand response analysis.

GridLAB-D has a relatively uncomplicated installation process. The user can choose from three options: default modules, sample models, and supplementary software. The default option includes the following modules: climate, generators, market, network, power flow, reliability, residential, and tape. Two supplementary software packages include (1) Minimalist GNU for Windows (MinGW), a minimalist development environment for native Microsoft Windows applications, and (2) GNUPlot, a portable command-line driven graphing utility. GridLAB-D is compatible with Windows and Linux/Unix (including Mac OSX) operating systems.

Programmed in $\mathrm{C}$ and $\mathrm{C}++$, the software requires text files to describe the different network elements and define simulation parameters within the command window, as shown in Figure 3. The lack of a friendly GUI presents some difficulties in user experience.

\footnotetext{
${ }^{7}$ The software can be downloaded free of charge from https://sourceforge.net/projects/gridlab-d/?source=directory.
} 


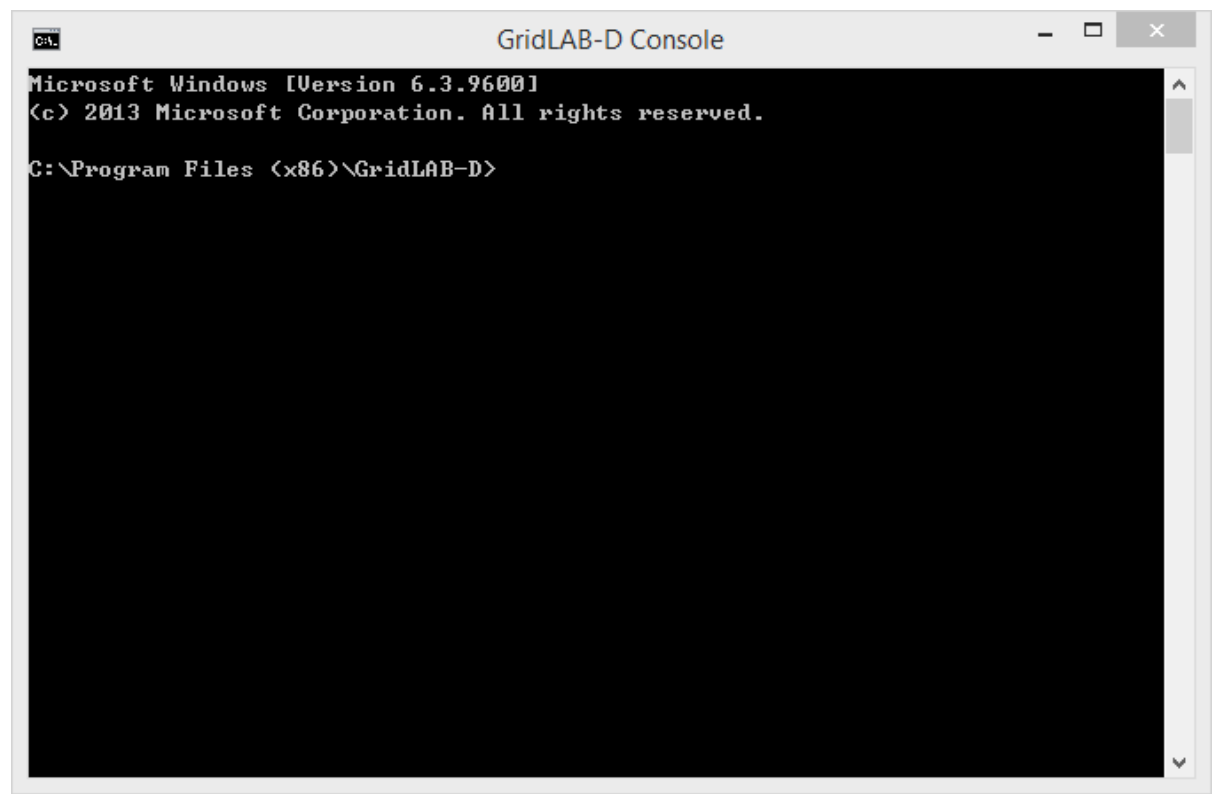

Figure 3. GridLAB-D user interface

\subsubsection{Features}

- Grid elements. GridLAB-D's library contains models for line, transformer, regulator, capacitor, fuse, generator, solar PV and wind power generators, and unbalanced loads. The library also contains extensive residential end-use load modules (e.g., dishwasher, refrigerator, dryer, cooker, heater, and electric vehicle charger).

- Capabilities. GridLAB-D can be used for load flow, time-series calculation, volt/VAR management, and power loss calculation.

- Preprocessing and post processing. GridLAB-D supports csv files, MATLAB, and Excel to preprocess or post process data.

- Compatibility with other applications. GridLAB-D can be used with other software platform such as MATLAB, web services, and MySQL.

- Power flow analysis. GridLAB-D can be used to run power flow analysis for radial or meshed networks, including those that have unbalanced loads (three phase).

- Capacitor bank control. GridLAB-D has the ability to use different modes of capacitor bank controls (e.g., voltage, current, kVAR, and volt/VAR).

- $\quad P V$ generators. Many PV generator models are available in GridLAB-D.

- Remote bus control. GridLAB-D can provide level control of a capacitor bank as well as capacitor bank control for a remote node.

- Smart grid simulation. GridLAB-D has market, real-time, and communications network modules, which are essential for smart grid simulation. In addition, its load control module supports demand-side management, and its reliability module contains calculations for reliability metrics such as the System Average Interruption Duration Index and System Average Interruption Frequency Index. 
- Special feature. The climate module is pertinent to the integration of renewable sources of electricity as well as air-conditioning load forecasting.

\subsubsection{Not featured}

- Short-circuit analysis. GridLAB-D can only perform short-circuit analysis for simple radial networks and cannot accommodate complex networks.

- On-screen design and editing. GridLAB-D does not support online editing and zooming or dragging and dropping shapes. The model is constructed in the specialized modeling file that uses a text-based format (.glm). The user then executes the model using the command line.

- Model import/export. GridLAB-D does not have a built-in conversion tool for importing models from other programs. However, it has the ability to import or export data from other applications such as CSV, MySQL, and MATLAB.

- Lack of documentation is a critical issue for beginner users of this tool.

\subsection{CYMDIST}

The Distribution System Analysis of the CYME Power Engineering Software, known as CYMDIST, was developed by CYME International, which is currently a subsidiary of Eaton. The package consists of a set of network analysis modules and user-customizable model libraries. CYMDIST is not open-license software. However, a trial version is available. ${ }^{8}$ The program is designed to simulate the behavior of electrical distribution networks under various operating conditions and scenarios. Several built-in functions support distribution network planning and operation.

The software features a flexible user interface and customizable workspace in which graphical representations of network and reporting elements can be dragged and dropped to build a power system model. Users can model the power system based on geographical information from online maps and add additional visualization features.

CYMDIST offers functions for power flow calculation, system analysis, system planning, and fault simulation. However, CYMDIST cannot simulate a power system dynamically in the sense that the software can only run a simulation with a set of fixed, time-series data. It has the ability to simulate variable generation and loads in both steady-state analysis and time-series analysis, and thus it can be used to study the impact of renewable energy on distribution feeders.

The following features are evaluated based on experience using the evaluation copy.

\subsubsection{Features}

- Grid elements. CYMDIST has line, transformer, regulator, capacitor, fuse, generator, and other models. Certain distributed generator models, including PV, wind energy conversion system, and micro-turbine, became available with CYME V5.02. In some cases, PV generators can be modeled as electronically coupled generators in CYMDIST [7].

\footnotetext{
${ }^{8}$ CYMDIST can be downloaded from http://www.cyme.com/.
} 
- Capabilities. CYMDIST can be used for load flow analysis, time-series calculations, power loss calculations, balanced or unbalanced voltage drop analysis for radial, looped and meshed networks, and protective device coordination.

- Preprocessing and post processing. CYMDIST can make use of csv files and it can export results to Excel to preprocess or post process data.

- Power flow analysis. CYMDIST can be used to run power flow analysis for distribution networks. The power flow can be solved using either balanced mode or unbalanced mode.

- Capacitor bank control. CYMDIST has the ability to use capacitor bank controls with voltage/current controls, as well as time, power factor, VAR, and temperature. In addition, with optional add-on module, CYMDIST is able to improve the performance of network through finding optimal setting for Volt/VAR control devices to optimize distribution network.

- Transient Stability. The dynamic behavior of distribution systems can be simulated under various transient events with optional add-on module.

- More optional add-on modules for in depth analysis. Predictive and historic reliability assessment, contingency analysis, switching optimization, etc. can be employed in CYMDIST.

- Voltage regulators. CYMDIST allows for single or multiple regulators of different types. . It also enables the optimal placement of voltage regulators on a distribution feeder.

- Short-circuit analysis. Short-circuit analysis can be done by using CYMDIST.

- On-screen design and editing. CYMDIST provides an advanced GUI with online editing features and zooming or dragging and dropping objects.

\subsubsection{Not featured}

- Compatibility with other applications. CYMDIST cannot be coupled with other applications such as MATLAB.

\subsection{PowerWorld Simulator}

PowerWorld Simulator is an interactive power system analysis and visualization software with a focus on high-voltage transmission systems. PowerWorld Simulator Version 1.0 was created by Thomas Overbye in 1994 to teach power system students and amateurs. In 1996, PowerWorld Corporation was founded to further develop the simulation tools. The latest version, Simulator 19 , contains a powerful analysis package that can model large systems with up to 250,000 buses on a time horizon ranging from several minutes to several days. Although Simulator 19 is a commercial product, PowerWorld offers a demonstration version. ${ }^{9}$

PowerWorld was not designed to be a distribution-level analysis tool. It has been designed as a transmission level tool under the assumption that the system is a three phase balanced system. It

\footnotetext{
${ }^{9}$ The demonstration version of PowerWorld Simulator 18 can be downloaded from http://www.powerworld.com/simulator-18-glover-sarma-overbye-edition-download.
} 
is analyzed here to illustrate the distinctions in functionality and features between transmission level and distribution level simulators.

\subsubsection{Features}

- Intuitive GUI. PowerWorld Simulator provides a user-friendly interface. It connects the graphical power system case editor to the power flow analysis tool package. (The two tools are usually separated in other software packages.)

- Ribbon. PowerWorld Simulator uses a ribbon interface to manage the large number of features. This streamlines the number of choices and helps users concentrate on the most common features.

- Model explorer. Model explorer contains a hierarchical list of commonly used objects from which users can easily manage numerous case information and displays.

- Economics and markets modeling. PowerWorld Simulator provides various tools to model the electricity market, such as optimal power flow, security-constrained optimal power flow, and time-step simulation.

- Security analysis. Tools for a PV and QV curve, Newton-Raphson method, and available transfer capability are available to conduct security analysis.

- Transient Stability. Transient stability tools were added in 2006. Different kinds of model types are supported in PowerWorld Simulator, such as generator models, wind generator models, and load models.

- Contour by percentage. PowerWorld Simulator offers contouring visualization for users to monitor data, present data, and obtain an overview of parameters at a glance, such as bus voltage magnitudes and line MVA percentage loadings. Users can set up custom color maps to show any contoured values highlighted in a specific manner. There is essentially no limit as to the number of values that can be mapped to specific colors.

- Text editor view. PowerWorld cases are saved in PowerWorld binary format (*.pwb), which stores power flow data, economic parameters, case time variation/option values, and screen customizations. The binary form cannot be viewed by a standard text editor. However, the user has the option to save data in AUX files, which are text files that can be set up by the user to run commands or change data. Although the process is more difficult to execute because it is not in the GUI, AUX files can be viewed in a standard text editor.

\subsubsection{Not Featured}

- A lack of solution for unbalanced power flow. Because PowerWorld simulator is designed for transmission systems, it is based on three-phase balanced AC power system model and cannot simulate an unbalanced system. With the exception of short circuit analysis, PowerWorld analyzes a single phase and multiplies the power flows by three. 


\section{Summary and Comparison}

Each of the packages reviewed has certain advantages and disadvantages. Choosing the best analysis tool to achieve a specific task depends on the nature of the case study under investigation. Some analytical tools provide a GUI that makes them easy to use and easy to visualize. For example, CYMDIST and PowerWorld have GUIs that allow dragging and dropping elements of the model on the screen. OpenDSS and GridLAB-D are command-line programs that allow users to build a case study by using only commands; however, OpenDSS allows the final circuit to be visualized. As the case study gets complicated, it is convenient to visualize the system to detect if there are any missing connections between buses. Some analysis tools have the ability to carry out short-circuit analysis, and some do not. For example, OpenDSS cannot perform short-circuit analysis. Table 1 through Table 4 summarize these features and the comparison among packages, including the available equipment models, on-screen editing, display and reporting, and additional features.

\subsection{Basic Features}

Table 1 summarizes the basic features of each package. All of the tools reviewed in this report have the ability to perform power flow analysis for both single- and three-phase systems with the exception of PowerWorld Simulator. The Newton-Raphson method is used to solve the power flow calculation. However, GridLAB-D has many other optional methods to solve the power flow. The rest of the differences are shown in Table 1. 
Table 1. Basic Features

\begin{tabular}{|c|c|c|c|c|}
\hline Feature & OpenDSS & GridLAB-D & CYMDIST & $\begin{array}{l}\text { PowerWorld } \\
\text { Simulator }\end{array}$ \\
\hline $\begin{array}{l}\text { Power flow analysis for } \\
\text { radial/looped network }\end{array}$ & Yes & Yes & Yes & Yes \\
\hline $\begin{array}{l}\text { Power flow analysis for } \\
\text { systems with unbalanced } \\
\text { loads }\end{array}$ & Yes & Yes & Yes & No \\
\hline $\begin{array}{l}\text { Source unbalance for slack } \\
\text { bus }\end{array}$ & Yes & Yes & No & No \\
\hline Multiple generation sources & Yes & Yes & Yes & Yes \\
\hline Motor starting analysis & Yes & $\mathrm{N} / \mathrm{A}$ & Yes & Yes \\
\hline $\begin{array}{l}\text { Three-phase power flow } \\
\text { analysis }\end{array}$ & Yes & Yes & Yes & Yes \\
\hline $\begin{array}{l}\text { Single-phase power flow } \\
\text { analysis }\end{array}$ & Yes & Yes & Yes & No \\
\hline $\begin{array}{l}\text { Power flow solution } \\
\text { methods }\end{array}$ & $\begin{array}{l}\text { Normal fixed- } \\
\text { point method, } \\
\text { Newton mode } \\
\text { method }\end{array}$ & $\begin{array}{l}\text { Forward- } \\
\text { backward } \\
\text { sweep, Newton- } \\
\text { Raphson, }\end{array}$ & $\begin{array}{l}\text { Newton- } \\
\text { Raphson }\end{array}$ & $\begin{array}{l}\text { Newton } \\
\text { Raphson, fast } \\
\text { decoupled, } \\
\text { polar Newton } \\
\text { Raphson, DC } \\
\text { Power Flow, } \\
\text { robust solution } \\
\text { process }\end{array}$ \\
\hline $\begin{array}{l}\text { Choosing the type of power } \\
\text { flow technique }\end{array}$ & No & Yes & No & No \\
\hline Voltage regulation & Yes & Yes & Yes & Yes \\
\hline $\begin{array}{l}\text { PV voltage regulation } \\
\text { support in power flow }\end{array}$ & Yes & Yes & No & $\begin{array}{l}\text { Yes (wind } \\
\text { control mode } \\
\text { under generator } \\
\text { voltage control) }\end{array}$ \\
\hline Short-circuit analysis & Yes & Yes & Yes & Yes \\
\hline $\begin{array}{l}\text { Open conductor fault } \\
\text { analysis }\end{array}$ & Yes & No & No & Yes \\
\hline Capacitor bank control & Yes & Yes & Yes & Yes \\
\hline $\begin{array}{l}\text { Capacitor bank control } \\
\text { modes }\end{array}$ & $\begin{array}{l}\text { Voltage, current, } \\
\text { kVAR, } \\
\text { Time }\end{array}$ & $\begin{array}{l}\text { Voltage, current, } \\
\text { kVAR, } \\
\text { volt/VAR }\end{array}$ & $\begin{array}{l}\text { Voltage, current } \\
\text { Volt/VAR, time, } \\
\text { temperature, } \\
\text { etc. }\end{array}$ & $\begin{array}{l}\text { fixed, discrete, } \\
\text { continuous, SVC }\end{array}$ \\
\hline $\begin{array}{l}\text { Capacitor bank control } \\
\text { based on remote node } \\
\text { sensing }\end{array}$ & Yes & Yes & No & No \\
\hline
\end{tabular}




\subsection{Available Equipment Models}

Each analysis tool in this report has a model library for most of the power components. Of the four software packages, GridLAB-D is the only one that has residential end-user models. Table 2 shows the available equipment models.

Table 2. Available Equipment Models

\begin{tabular}{|c|c|c|c|c|}
\hline Feature & OpenDss & GridLAB-D & CYMDIST & $\begin{array}{l}\text { PowerWorld } \\
\text { Simulator }\end{array}$ \\
\hline $\begin{array}{l}\text { Transmission lines or cables } \\
\text { (pi-equivalent) }\end{array}$ & Yes & Yes & Yes & Yes \\
\hline $\begin{array}{l}\text { Generators (synchronous or } \\
\text { induction) }\end{array}$ & Yes & Yes & Yes & Yes \\
\hline Three-phase transformers & $\begin{array}{l}\text { Yes-all } \\
\text { connections }\end{array}$ & $\begin{array}{l}\text { most common } \\
\text { types }\end{array}$ & $\begin{array}{l}\text { Yes-all } \\
\text { connections }\end{array}$ & Yes \\
\hline Models of PV generators & Yes & Yes & Yes & $\begin{array}{l}\text { Yes (wind } \\
\text { control mode) }\end{array}$ \\
\hline Capacitors & Yes & Yes & Yes & Yes \\
\hline Switches & Yes & Yes & Yes & Yes \\
\hline Overcurrent devices & Yes & Yes & Yes & Yes \\
\hline Motors & Yes & Yes & Yes & Not explicitly \\
\hline $\begin{array}{l}\text { Preloaded geographical PV } \\
\text { insolation data }\end{array}$ & No & Yes & No & No \\
\hline Residential end-user models & No & Yes & No & No \\
\hline
\end{tabular}

\subsection{On-Screen Design and Editing}

From an on-screen design point of view, PowerWorld Simulator is the best package among the reviewed packages in this report, allowing editing and zooming, panning, and dragging and dropping shapes. PowerWorld Simulator and CYMDIST are the only two packages that have GUIs. OpenDSS allows the user to visualize the system after the commands are completed, but GridLAB-D does not allow the user to visualize the modeled system.

Table 3. On-Screen Design and Editing

\begin{tabular}{|c|c|c|c|c|}
\hline Feature & OpenDSs & GridLAB-D & CYMDIST & $\begin{array}{l}\text { PowerWorld } \\
\text { Simulator }\end{array}$ \\
\hline $\begin{array}{l}\text { On-line editing and zooming (buses, } \\
\text { nodes, branches) }\end{array}$ & No & No & Yes & Yes \\
\hline Panning of diagrams & Yes & No & Yes & Yes \\
\hline $\begin{array}{l}\text { Dragging and dropping shapes quickly } \\
\text { with automatic snap and align into position }\end{array}$ & No & No & Yes & Yes \\
\hline
\end{tabular}




\subsection{Display and Reporting}

CYMDIST, OpenDSS, and PowerWorld Simulator provide many features for displaying and reporting the results. GridLAB-D has fewer features to display and report the results. Table 4 shows these features for each package.

Table 4. Display and Reporting

\begin{tabular}{|c|c|c|c|c|}
\hline Feature & OpenDSS & GridLAB-D & CYMDIST & $\begin{array}{l}\text { PowerWorld } \\
\text { Simulator }\end{array}$ \\
\hline $\begin{array}{l}\text { Power flow displays (arrow indicating } \\
\text { direction) }\end{array}$ & No & No & Yes & Yes \\
\hline $\begin{array}{l}\text { Color displays (overloads, different } \\
\text { feeders) }\end{array}$ & Yes & No & Yes & Yes \\
\hline Abnormal conditions flagging & Yes & No & No & Yes \\
\hline $\begin{array}{l}\text { Display selected number of phases or } \\
\text { selected equipment }\end{array}$ & Yes & No & Yes & $\begin{array}{l}\text { No for phase } \\
\text { selection; } \\
\text { yes for } \\
\text { selected } \\
\text { equipment }\end{array}$ \\
\hline Display control (zoom, pan, end points) & Yes & No & Yes & Yes \\
\hline Graphical displays of entire report & Yes & No & Yes & Yes \\
\hline Distribution system profiles & Yes & No & Yes & Yes \\
\hline
\end{tabular}

\subsection{Additional Features}

Each package can import and export data from different types of packages. OpenDSS, GridLAB$\mathrm{D}$, are free-license packages. PowerWorld offers a free education version for students and teachers. A free trial version is available for CYMDIST. Some additional features are given in Table 5. OpenDSS accepts input data in many formats, such as csv files, MATLAB files, and Excel. GridLAB-D accepts data as csv files and MATLAB. The output data can be transferred to many file formats. 
Table 5. Additional Features

\begin{tabular}{|c|c|c|c|c|}
\hline Feature & OpenDSs & GridLAB-D & CYMDIST & $\begin{array}{l}\text { PowerWorld } \\
\text { Simulator } \\
\text { (Education) }\end{array}$ \\
\hline Type of license & Free & Free & $\begin{array}{l}\text { Trial version } \\
\text { available }\end{array}$ & Free \\
\hline $\begin{array}{l}\text { Types of accepted } \\
\text { data formats }\end{array}$ & $\begin{array}{l}\text { csv files, txt files, } \\
\text { MATLAB, Excel, } \\
\text { etc. }\end{array}$ & $\begin{array}{l}\text { csv files, MATLAB, } \\
\text { MySQL, etc. }\end{array}$ & $\begin{array}{l}\text { CAD files, GIS } \\
\text { files, txt files }\end{array}$ & $\begin{array}{l}\text { csv files, Excel files, } \\
\text { etc. }\end{array}$ \\
\hline $\begin{array}{l}\text { File to which output } \\
\text { data can be } \\
\text { transferred }\end{array}$ & $\begin{array}{l}\text { csv files, } \\
\text { MATLAB, Excel }\end{array}$ & $\begin{array}{l}\text { csv files, MATLAB, } \\
\text { graphical tools }\end{array}$ & txt files, csv files & MATLAB, Excel \\
\hline $\begin{array}{l}\text { Examples cases in } \\
\text { the package }\end{array}$ & Several examples & several examples & $\begin{array}{l}\text { Several } \\
\text { examples }\end{array}$ & Many examples \\
\hline Internet forum & Active & Active & Active & Active \\
\hline Developer & $\begin{array}{l}\text { Electric Power } \\
\text { Research Institute }\end{array}$ & $\begin{array}{l}\text { Pacific Northwest } \\
\text { National } \\
\text { Laboratory }\end{array}$ & $\begin{array}{l}\text { Eaton } \\
\text { Corporation }\end{array}$ & $\begin{array}{l}\text { PowerWorld } \\
\text { Corporation }\end{array}$ \\
\hline
\end{tabular}




\section{Conclusion}

In this report, four packages are extensively studied to compare their ability to simulate a distribution network with variable renewable DG. Each package has some advantages and disadvantages.

Based on comparative analysis in this paper, OpenDSS and GridLAB-D have relatively high capability to simulate networks with fluctuating data values. The case study used data that changed on a minute interval. The procedure was straightforward and worked in an iterative manner. These packages allowed the performer to run the simulation at each time instant by iterating only the main script file. PowerWorld Simulator has a batch mode simulation function through a feature that is called "Time Step Simulation." CYME, developer of CYMDIST, has many solutions to implement batch analyses with time-series simulations, including PYTHON scripting capabilities and Component Object Modeling capabilities.

CYMDIST and PowerWorld Simulator feature easy-to-use GUIs. OpenDSS and GridLAB-D, on the other hand, are based on command-line programs, which required more time to gain familiarity with the software packages. In addition, the ability of OpenDSS and GridLAB-D to interact with MATLAB increases their utility for users. The open-source nature of OpenDSS and GridLAB-D can also help these tools to improve in the future.

For modelling multiple-generator systems, CYMDIST's GUI provides efficient programming procedures and a friendly environment for new users. Customized software layout is also achievable in CYMDIST. The software allows different analyses to be conducted and easily switched from the simulation toolbar or menu. CYMDIST includes distributed generator models, such as PV and micro-turbines, which can simplify the system modelling process. In addition, data can be imported using Automated Mapping/Facilities Management GIS software [8]. Selection of "simulation report" from the toolbar allows for generation of results in different formats, allowing for visualization. 


\section{References}

1. M.A. Moffet, F. Sirois, and D. Beauvais. Review of Open-Source Code Power Grid Simulation Tools for Long-Term Parametric Simulation. (Technical Report). 2011-137. Varennes, Quebec: CanmetENERGY, 2011.

2. Rizy, D.T., and R.H. Staunton. Evaluation of Distribution Analysis Software for DER Applications. (Technical Report). ORNL/TM-2001/215. Oak Ridge, TN: Oak Ridge National Laboratory, 2002.

3. “OpenDSS.” 2016. SourceForge. Accessed April 202016. https://sourceforge.net/projects/electricdss/.

4. Dugan, R.C. "Open Distribution Simulations System Workshop: Using OpenDSS for Smart Distribution Simulations.” Paper presented at the EPRI PQ Smart Distribution 2010 Conference and Exhibition, Québec, June 14-17, 2010.

5. Dugan, R.C. “Tutorial: The OpenDSS Application.” Paper presented at the 4th International Conference on Integration of Renewable and Distributed Energy Resources, Albuquerque, NM, 2010.

6. Dugan, R.C., R.F. Arritt, T.E. McDermott, S.M. Brahma, and K. Schneider, K. "Distribution System Analysis to Support the Smart Grid." IEEE Power and Energy Society General Meeting (2010).

7. Tang, Y., Mao, X., and Ayyanar. R. "Distribution System Modelling using CYMDIST for Study of High Penetration of Distributed Solar Photovoltaics." North American Power Symposium, Champaign, IL, Sep. 9-11, 2012.

8. Ramesh, L., Ravindiran. S., Chowdhury. S.P., Chowdhury. S., Song. Y.H., and Goswami. P.K., "Distribution System Loss Minimization and Planning Using CYMDIST." Universities Power Engineering Conference, Brighton, Sep. 4-6, 2007. 